Article

\title{
An Improved Conversion Relationship between Tropical Cyclone Intensity Index and Maximum Wind Speed for the Advanced Dvorak Technique in the Northwestern Pacific Ocean Using SMAP Data
}

\author{
Sumin Ryu ${ }^{1}$, Sung-Eun Hong ${ }^{2}{ }^{\infty}$, Jun-Dong Park ${ }^{3}$ and Sungwook Hong $1,4, * \mathbb{(}$ \\ 1 Department of Environment, Energy and Geoinfomatics, Sejong University, Seoul 05006, Korea; \\ ryusm26@sju.ac.kr \\ 2 Department of Research and Development, GI E\&S Co., Ltd., Seoul 04173, Korea; argus@gi-ens.co.kr \\ 3 National Meteorological Satellite Center, Korea Meteorological Administration, Jincheon-gun, \\ Chungcheongbuk-do 27803, Korea; jun.park@kma.go.kr \\ 4 Department of Research and Development, DeepThoTh Co., Ltd., Seoul 05006, Korea \\ * Correspondence: sesttiya@sejong.ac.kr; Tel.: +82-2-6935-2430
}

Received: 13 July 2020; Accepted: 10 August 2020; Published: 11 August 2020

check for updates

\begin{abstract}
The Advanced Dvorak Technique (ADT) uses geostationary satellite data to estimate tropical cyclone (TC) intensity owing to the difficulty in directly observing a TC's internal structure. This study presents a new relationship (Hong and Ryu scale) between the current intensity (CI) number and estimated maximum wind speed (MWS) of TCs over the northwestern Pacific region; the CI number is the TC intensity index retrieved from the ADT. The Soil Moisture Active Passive (SMAP) with the L-band $(1.4 \mathrm{GHz})$ microwave radiometer, is used to calibrate and produce the new Hong and Ryu scale for the ADT algorithm. Japan Meteorological Agency (JMA) best track MWS data, SMAP sea surface wind speed estimates, and ADT's TC intensity data between 2015-2018 are spatiotemporally collocated for the calibration process. The CI number is derived from the Korea Meteorological Administration (KMA) operational ADT which uses the Koba scale to convert to the MWS for validation against the MWS of the best track. The conversion relationships between CI number and SMAP MWS, and between SMAP MWS and MWS of the best track a derived, and the MWS of two ADTs with the Koba and Hong and Ryu scales are then estimated using the same CI numbers with TC intensity data between 2015-2018. Finally, the MWS of the ADT with the Koba scale and the new ADT with the proposed Hong and Ryu scale are independently validated on best track data from 2013-2014. The MWS root mean square error (RMSE) is $4.39 \mathrm{~m} / \mathrm{s}$ for the new ADT using the Hong and Ryu scale, which is lower than $4.77 \mathrm{~m} / \mathrm{s}$ RMSE of the ADT using the Koba scale. Hence, the ADT using the Hong and Ryu scale can modestly improve the accuracy of TC intensity analysis in the northwestern Pacific region.
\end{abstract}

Keywords: Advanced Dvorak Technique; tropical cyclone; maximum wind speed; intensity; best track; SMAP

\section{Introduction}

Tropical cyclones (TCs) are one of the most dangerous natural disasters. The damage to life and property in areas impacted by TCs are enormous in low-latitude and mid-latitude regions due to heavy rain, strong wind, and large storm surges characterizing TCs. In Korea, the annual loss due to TCs is approximately 50 percent of all disaster losses. The maximum wind speed (MWS) of typhoon Haiyan (typhoon and TCs will be used interchangeably in this paper), in 2013 was $315 \mathrm{~km} / \mathrm{h}$ causing 
significant damage to the Philippines. Typhoon Haiyan caused approximately 34,870 casualties and led to approximately $\$ 776$ million in property damage [1]. For these reasons, accurate analysis of TC intensity is essential to reduce forecast error and socio-economic impact of TCs.

TC intensity is determined by estimating the MWS and minimum sea level pressure (MSLP) primarily using satellites outside of TC basins that utilize reconnaissance aircraft. The legacy satellite method that has been used worldwide for several decades is the Dvorak Technique (DT) [2-5]. The DT estimates TC intensity using geostationary visible (VIS) or infrared (IR) satellite observations. In the DT, the current intensity (CI) number is the TC intensity index which is determined by analyzing the cloud image pattern and cloud system center (CSC) in the TC's IR satellite observation. The CI number is directly related to the MWS and the MSLP of the TC. The conversion modules have been presented by Dvorak [2-5], Koba [6], Harper [7], Knaff and Zehr [8], Holland [9], and Courtney [10] and are based on statistical analyses in comparison with ground and aircraft-based observations. The conversion modules between CI number and the MWS can differ for each TC basin. For instance, in the northwestern Pacific including Korea, Japan, and China, the Koba scale [6,11] is traditionally used as a module of the conversion. The Koba scale expresses the MWS of TCs from approximately $11 \mathrm{~m} / \mathrm{s}$ up to approximately $63 \mathrm{~m} / \mathrm{s}$. In the northeastern Pacific and Atlantic TC basins, the Dvorak scale [4] is used.

The DT is limited in that it does not provide direct wind measurements and the interpretation of VIS or IR geostationary satellite imagery from the cloud pattern of a TC and center location of a TC can be subjective [5]. The DT often underestimates true TC intensity in central dense overcast conditions in the satellite imagery in those cases with a weak eye or developing eyewall structure, or at large scan angles from the geostationary satellite [5]. A derivative method of the DT is the Advanced Dvorak Technique (ADT) [12,13], which is a fully automated computer-based objective algorithm patterned after the DT principles based on IR imagery. The ADT has been producing TC intensity estimates at KMA for many years. Like the parent DT method, the ADT also produces a CI number, and the version at KMA converts to MWS in the northwest Pacific TC basin using the Koba scale.

Recently available satellite observations can be used to tune the ADT and refine the conversion relationships. While IR sensors find it physically difficult to acquire sea surface data under cloudy and rainy conditions, satellite-based microwave instruments can obtain observations such as surface wind speed because the microwave frequencies react directly with ocean surface water particles $[14,15]$. For example, the Soil Moisture Active Passive (SMAP) has an L-band radiometer (1.4 GHz microwave length band), which is the longest wavelength among existing passive microwave radiometers onboard satellites. Thus, SMAP can estimate a higher wind speed than other passive microwave instruments [16]. A previous study demonstrated that SMAP has a low sea surface wind speed measurement error (1.5 m/s of RMSE) compared to WindSat [17].

This study presents an improved TC MWS estimation method using the ADT with a novel conversion relationship between the CI number and MWS for the northwestern Pacific TCs. MWS estimated from the SMAP and Japan Meteorological Agency (JMA) best track data or TCs in the northwestern Pacific region between 2015 to 2018 were used to develop the new relationship. The ADT with the proposed conversion scale was then validated using MWS data of the best track, and compared to the ADT with the Koba scale for TCs in the study area between 2013 to 2014 (prior to SMAP).

\section{Data}

\subsection{Cases of TCS}

In this study, SMAP sea surface wind speed data produced by Remote Sensing Systems and sponsored by NASA Earth Science funding [18] was used to re-examine the conversion relationship between the ADT CI number and the MWS of northern Pacific TCs. SMAP sea surface wind data during TCs in the northwestern Pacific between 2015 to 2018 were used to create the new Hong and Ryu scale, as the sea surface wind speed data from SMAP was available from June 2015 onward. The best track data provided by the Regional Specialized Meteorological Center (RSMC) at JMA was used to 
generate and verify the Hong and Ryu scale. TC best track data between 2013 to 2014 (pre-launch period of SMAP) was used to independently verify the degree of improvement for the Hong and Ryu scale. Table 1 presents a list of northwestern Pacific TCs during the study period (TCs 1 to 7 in 2015, and 23 to 26 in 2016, were not used in this study due to the absence of SMAP wind speed and/or ADT intensity datasets).

Table 1. List of northwestern Pacific tropical cyclones (TCs) during the study period.

\begin{tabular}{|c|c|c|c|c|c|c|}
\hline \multirow{3}{*}{$\begin{array}{c}\text { Typhoon } \\
\text { No. }\end{array}$} & \multicolumn{6}{|c|}{ Typhoon Name } \\
\hline & \multicolumn{4}{|c|}{ Study } & \multicolumn{2}{|c|}{ Verification } \\
\hline & 2015 & 2016 & 2017 & 2018 & 2013 & 2014 \\
\hline 01 & MEKKHALA & NEPARTAK & MUIFA & BOLAVEN & SONAMU & LINGLING \\
\hline 02 & HIGOS & LUPIT & MERBOK & SANBA & SHANSHAN & KAJIKI \\
\hline 03 & BAVI & MIRINAE & NANMADOL & JELAWAT & YAGI & FAXAI \\
\hline 04 & MAYSAK & NIDA & TALAS & EWINIAR & BEBINCA & TAPAH \\
\hline 05 & HAISHEN & OMAIS & NORU & MALIKSI & RUMBIA & MITAG \\
\hline 06 & NOUL & CONSON & KULAP & GAEMI & RUMBIA & MITAG \\
\hline 07 & DOLPHIN & CHANTHU & ROKE & PRAPIROON & SOULIK & HAGIBIS \\
\hline 08 & KUJIRA & DIANMU & SONCA & MARIA & CIMARON & NEOGURI \\
\hline 09 & CHAN-HOM & MINDULLE & NESAT & SON-TINH & JEBI & RAMMASUN \\
\hline 10 & LINFA & LIONROCK & HAITANG & AMPIL & MANGKHUT & MATMO \\
\hline 11 & NANGKA & KOMPASU & NALGAE & WUKONG & UTOR & HALONG \\
\hline 12 & HALOLA & NAMTHEUN & BANYAN & JONGDARI & TRAMI & NAKRI \\
\hline 13 & SOUDELOR & MALOU & HATO & SHANSHAN & PEWA & GENEVIEVE \\
\hline 14 & MOLAVE & MERANTI & PAKHAR & YAGI & UNALA & FENGSHEN \\
\hline 15 & GONI & RAI & SANVU & LEEPI & KONG-REY & KALMAEGI \\
\hline 16 & ATSANI & MALAKAS & MAWAR & BEBINCA & YUTU & FUNG-WONG \\
\hline 17 & KILO & MEGI & GUCHOL & HECTOR & TORAJI & KAMMURI \\
\hline 18 & ETAU & CHABA & TALIM & RUMBIA & MAN-YI & PHANFONE \\
\hline 19 & VAMCO & AERE & DOKSURI & SOULIK & USAGI & VONGFONG \\
\hline 20 & KROVANH & SONGDA & KHANUN & CIMARON & PABUK & NURI \\
\hline 21 & DUJUAN & SARIKA & LAN & JEBI & WUTIP & SINLAKU \\
\hline 22 & MUJIGAE & HAIMA & SAOLA & MANGKHUT & SEPAT & HAGUPIT \\
\hline 23 & CHOI-WAN & MEARI & DAMREY & BARIJAT & FITOW & JANGMI \\
\hline 24 & KOPPU & MA-ON & HAIKUI & TRAMI & DANAS & \\
\hline 25 & CHAMPI & TOKAGE & KIROGI & KONG-REY & NARI & \\
\hline 26 & IN-FA & NOCK-TEN & KAI-TAK & YUTU & WIPHA & \\
\hline 27 & MELOR & & TEMBIN & TORAGI & FRANCISCO & \\
\hline 28 & & & & MAN-YI & LEKIMA & \\
\hline 29 & & & & USAGI & KROSA & \\
\hline 30 & & & & & HAIYAN & \\
\hline 31 & & & & & PODUL & \\
\hline
\end{tabular}

\subsection{SMAP and COMS Data}

Geostationary satellites are useful for continuous TC monitoring due to their orbital advantage. The Communication, Ocean and Meteorological Satellite (COMS) is Korea's first geostationary multi-purpose satellite equipped with a meteorological imager (MI), with one VIS and four IR bands, $36,000 \mathrm{~km}$ above the Earth's equator at $128.2^{\circ} \mathrm{E}$. The Korea Meteorological Administration (KMA) has 
been operating the COMS since 27 June 2010. The COMS has been continuously observing the Korean peninsula, Northern Hemisphere East Asia, and the full disk of the Earth every 15 min, 30 min, 3 h, respectively [19]. Table 2 summarizes the band characteristics of the COMS.

Table 2. Band characteristics of the Communication, Ocean and Meteorological Satellite (COMS).

\begin{tabular}{cccc}
\hline Channel & Wavelength $(\mu \mathrm{m})$ & Bandwidth $(\mu \mathrm{m})$ & Spatial Resolution $(\mathbf{k m})$ \\
\hline Visible & 0.675 & $0.55-0.80$ & 1 \\
infrared & 3.75 & $3.5-4.0$ & 4 \\
Infrared & 6.75 & $6.5-7.0$ & 4 \\
Infrared & 10.8 & $10.3-11.3$ & 4 \\
Infrared & 12.0 & $11.5-12.5$ & 4 \\
\hline
\end{tabular}

The SMAP polar-orbiting satellite was launched by the National Aeronautics and Space Administration (NASA) in January 2015 and became operational in April 2015 [20]. The SMAP mission initially recorded soil moisture and freeze/thaw classification data [19], but sea surface wind speed data is also currently available due to the development of a wind speed algorithm from the passive microwave sensor [21,22]. The SMAP satellite has an active sensor (radar) and a passive sensor (radiometer), however the active sensor is currently not operational as of July 2015 due to problems. The spatial resolution of sea surface wind speed data from SMAP is $25 \mathrm{~km}\left(0.25^{\circ}\right.$ by $\left.0.25^{\circ}\right)$. Figure 1 shows an example of a typhoon observed by SMAP on 9 July 2015.

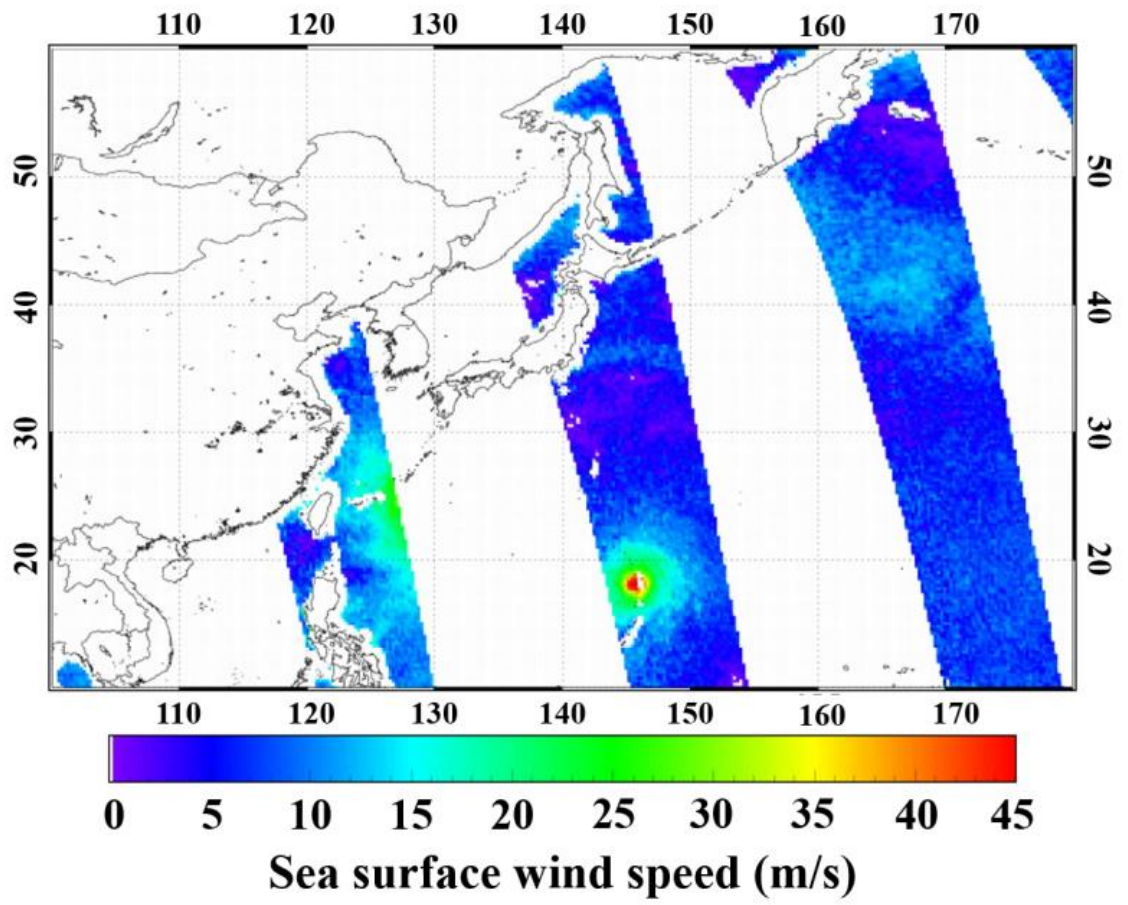

Figure 1. An example of a typhoon observed by Soil Moisture Active Passive (SMAP) sea surface wind speed retrievals on 9 July 2015.

\subsection{Best Track: TC Analysis Dataset}

The RSMC is the WMO-sanctioned specialized agency responsible for TC analyses and forecasts and is represented in six regions throughout the world. The agency responsible for the northwestern Pacific region is the JMA, providing the TC best track data for this region [23]. The best track data includes the TC location, MSLP, and the MWS at 3-h intervals. The best track analysis uses ground-based observations, radar data, aircraft reconnaissance observations, and satellite observations. In this study, the best track issued as "truth" data when compared to SMAP wind speed and ADT MWS estimates. 


\subsection{Spatiotemporal Collocation of SMAP, ADT, and Best Track Data}

We matched the spatial collocation between the gridded SMAP satellite data and the best track data by inputting the TC CSC data (latitude and longitude) from the best track into the SMAP grid data. From this match, the MWS generated within \pm 4 degrees of the latitude and the longitude from the TC center location is used for the SMAP MWS value.

The temporal resolution of SMAP orbital data is $1 \mathrm{~min}$ from $0 \mathrm{~min}$ to $1440 \mathrm{~min}$ during a day because SMAP overpasses twice per day at best and the SMAP overpass often misses a TC. Thus, the sample size of this study is small because of the greatly reduced possibility of matches. However, the temporal resolution of the ADT data is $1 \mathrm{~h}$, and for the best track data it is $3 \mathrm{~h}$. To increase the matching precision, we used a time window of $30 \mathrm{~min}$ between the SMAP data and best track data. Figure 2 shows a time series of the matched MWSs of SMAP, ADT, and best track data from 1 July to 31 December 2016. In this example, the overall mean value of MWSs of best track, SMAP, and ADT were $31.83,32.93$, and $26.99 \mathrm{~m} / \mathrm{s}$, respectively. Thus, we could confirm that the MWS values from SMAP were in good agreement with the MWS values of the best track because JMA used the SMAP values and weighted them heavily in analyzing the JMA best track.

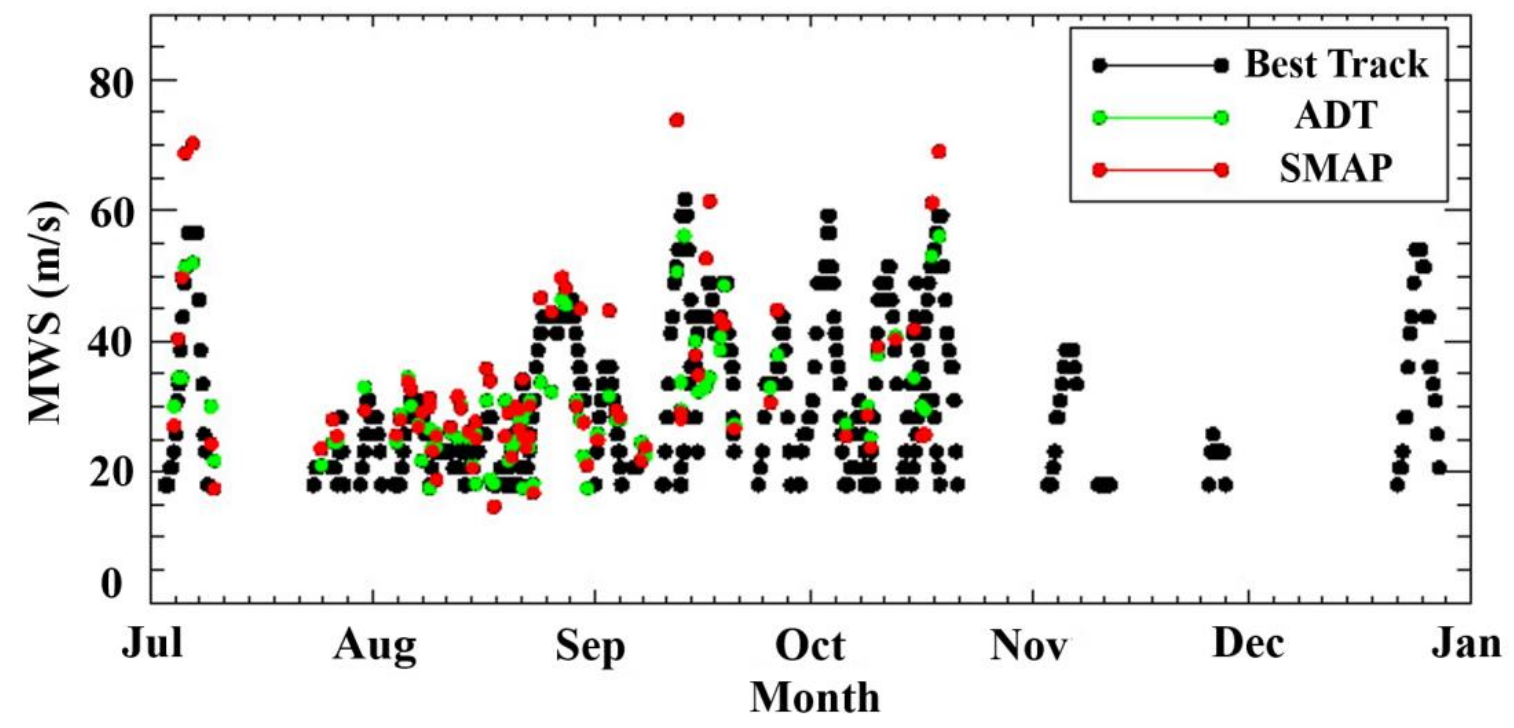

Figure 2. Time series of the collocated maximum wind speeds (MWSs) of SMAP, Advanced Dvorak Technique (ADT), and best track data from 1 July to 31 December 2016.

\section{Methodology}

\subsection{ADT TC Analysis Program}

The KMA has been operationally utilizing the ADT using the COMS geostationary satellite imagery to estimate the CSC and the CI number of TCs. In the ADT, the CI number is calculated by analyzing the IR-cloud pattern of a TC (or 'scene type') such as the presence of an eye, the size of the Central Dense Overcast (CDO), the sheared CDO, the central features (CFs), the outer banding features (BFs), and the curved cloud bands [2-5]. The CI number may range from 1.0 to 8.0. The ADT can often underestimate or overestimate the TC intensity due to the imprecise determination of the CSC or cloud pattern [12]. Figure 3 shows an example of CSC and cloud pattern determination from the COMS imagery, and the procedure for estimating MWS using the ADT at the KMA [24]. Figure 4 shows examples of the ADT CI numbers with the corresponding enhanced infrared (EIR) [4,5] images from COMS. 


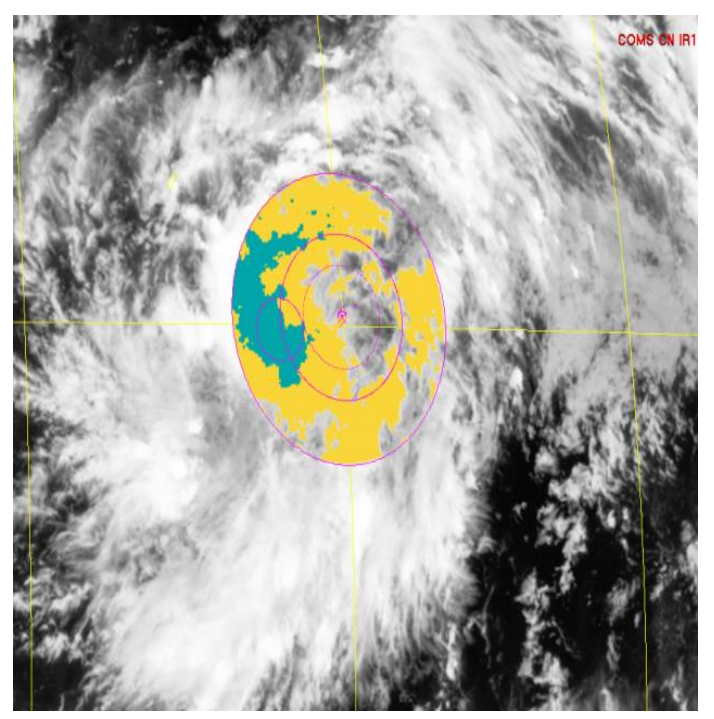

(a)

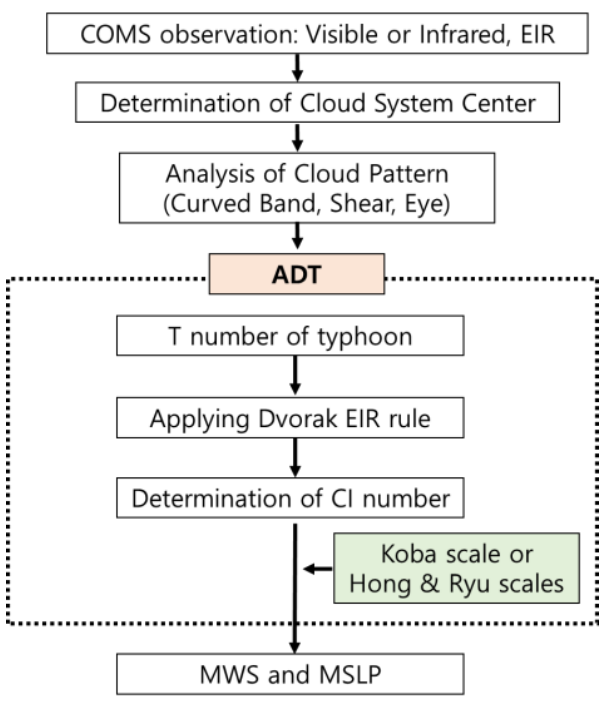

(b)

Figure 3. (a) Example of TC cloud system center (CSC) determination from the COMS imagery and (b) procedure for estimating MWS using ADT and COMS satellite observations.

\section{$\mathrm{Cl}$ number}

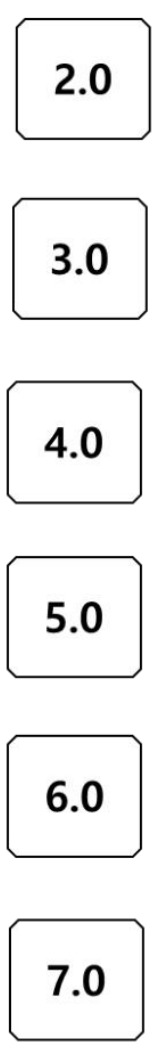

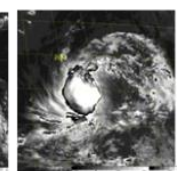
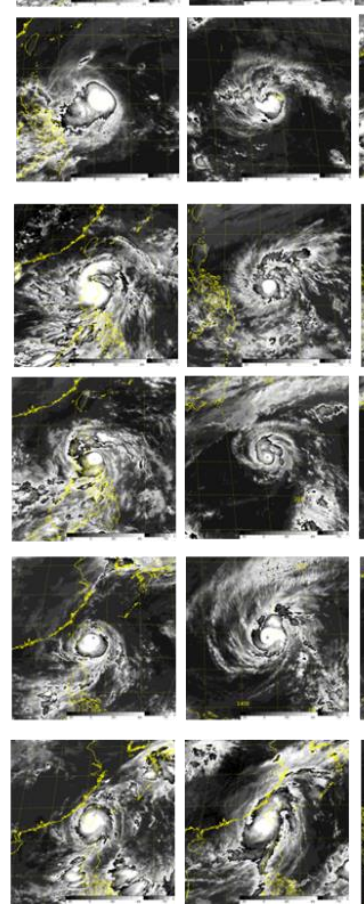
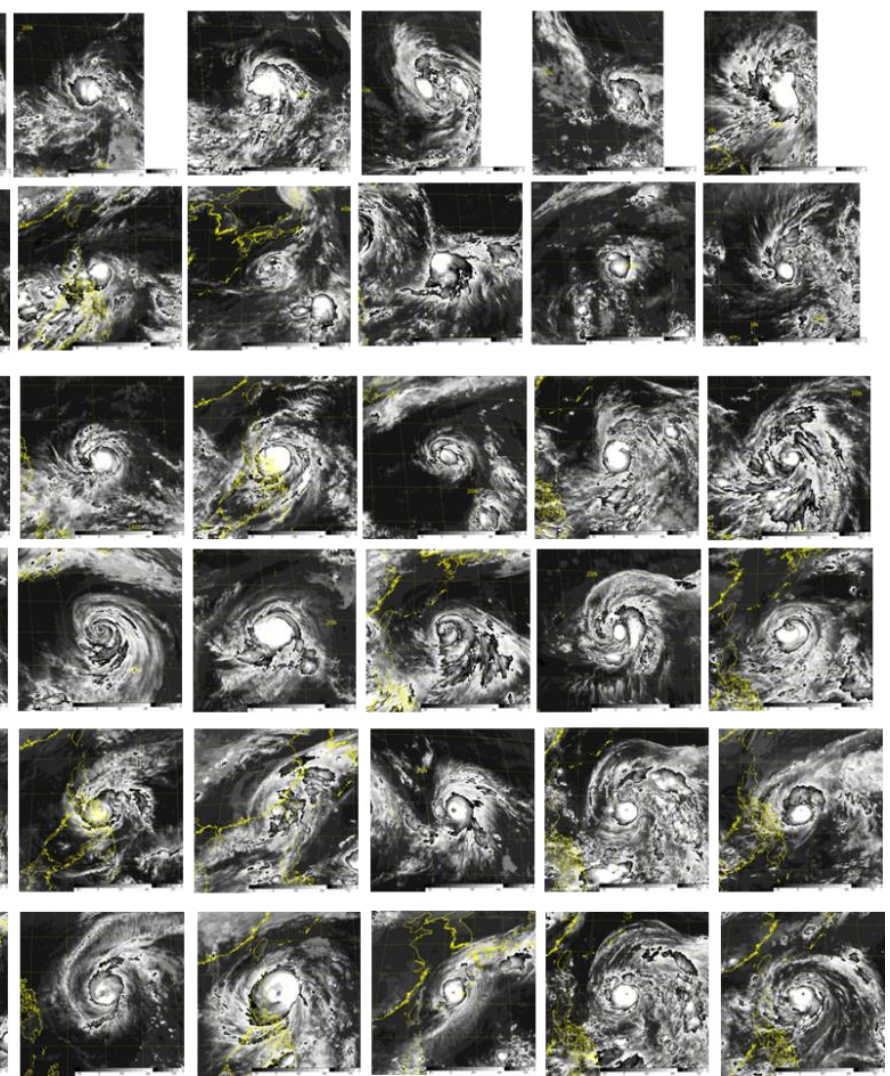

Figure 4. Examples of current intensity (CI) number and the corresponding enhanced Infrared (EIR) images from the COMS satellite. 


\subsection{Determination of CI number}

The Hong and Ryu conversion scale depends upon the relationship between the CI number and MWS data from SMAP. However, the best track data does not provide the CI number corresponding to the MWS. The CI number is a parameter generated in the ADT. Therefore, we estimated the best track CI number based on the Koba scale used in the current ADT that corresponded to the best track MWS for the collocated dataset from 2015 to 2018.

In this study, the CI number was determined from the dataset of the collocated best track MWS and the ADT with the Koba scale using a conversion relationship between CI number and the MWS as follows:

$$
C I=a_{0}+a_{1} \cdot M W S_{\text {Best }}
$$

where $a_{0}$ and $a_{1}$ are the regression coefficients to estimate the relationship between the CI number and the MWS. MWS Best is the MWS provided by best track data. The CI number data and the MWS data are obtained from the collocated dataset between the best track MWS and the CI number of the ADT using the Koba scale from 2015 to 2018. From this dataset, we obtain $a_{0}=-0.50537$ and $a_{1}=0.13621$.

\subsection{Hong and Ryu Scale}

The Hong and Ryu scale is produced using the calculated CI number and the collocated SMAP MWS data. For this process, the following three steps are implemented:

First, the relationship between the SMAP MWS and the CI number was estimated over the same period to convert the CI number into the corresponding SMAP MWS as:

$$
M W S_{S M A P}=b_{0}+b_{1} \cdot C I
$$

where $b_{0}$ and $b_{1}$ are regression coefficients to determine a relationship between the CI number and the SMAP MWS. The CI number data and the SMAP MWS data were obtained from the collocation between the SMAP MWS and the CI number of the ADT using the Koba scale between 2015 to 2018. From this dataset, $b_{0}=4.91528$ and $b_{1}=7.59828$.

Second, the relationship between the SMAP MWS and the best track MWS is determined over the same period to convert the best track's MWS into the corresponding SMAP MWS as:

$$
M W S_{\text {Best }}=c_{0}+c_{1} \cdot M W S_{S M A P}
$$

where $c_{0}$ and $c_{1}$ are regression coefficients for the conversion relationship between SMAP MWS and the MWS of the best track. Both MWS data were obtained from the collocated dataset of ADT, SMAP, and best track between 2015 to 2018. From this dataset, $c_{0}=1.20526$ and $c_{1}=0.88337$.

Finally, the Hong and Ryu scale is determined using Equations (1)-(3) as follows:

$$
\begin{gathered}
M W S_{H-R}=c_{0}+c_{1} \cdot\left(b_{0}+b_{1} \cdot C I\right) \\
=d_{0}+d_{1} \cdot C I
\end{gathered}
$$

where $d_{0}$ and $d_{1}$ are regression coefficients. $M W S_{H-R}$ is the new MWS estimated from the ADT CI with the Hong and Ryu scale (Equation (4)). In this study, $d_{0}=5.54727$ and $d_{1}=6.71209$ using the collocated dataset between 2015 to 2018 .

\subsection{Validation}

The performance validation of the new conversion scale was performed on an independent dataset of northwestern Pacific TC cases in 2013-2014 using the MWS estimates from two ADTs; the current ADT with the Koba scale, and the new ADT based on the Hong and Ryu scale. Both ADTs use the same CI number obtained from the cloud pattern and CSC information. Notably, the SMAP was not yet launched so its MWS data did not influence the JMA best track MWS estimates during this period. 
Thus, the two ADTs MWS value were compared and analyzed using the best track MWS data as "truth" estimates over the same period.

Low values of bias and RMSE indicate greater accuracy whilst a high correlation coefficient (CC) value implies a higher degree of correlation between the test and truth datasets. Figure 5 shows the procedure of validation using ADT and best track data using 2013-2014 TC cases.

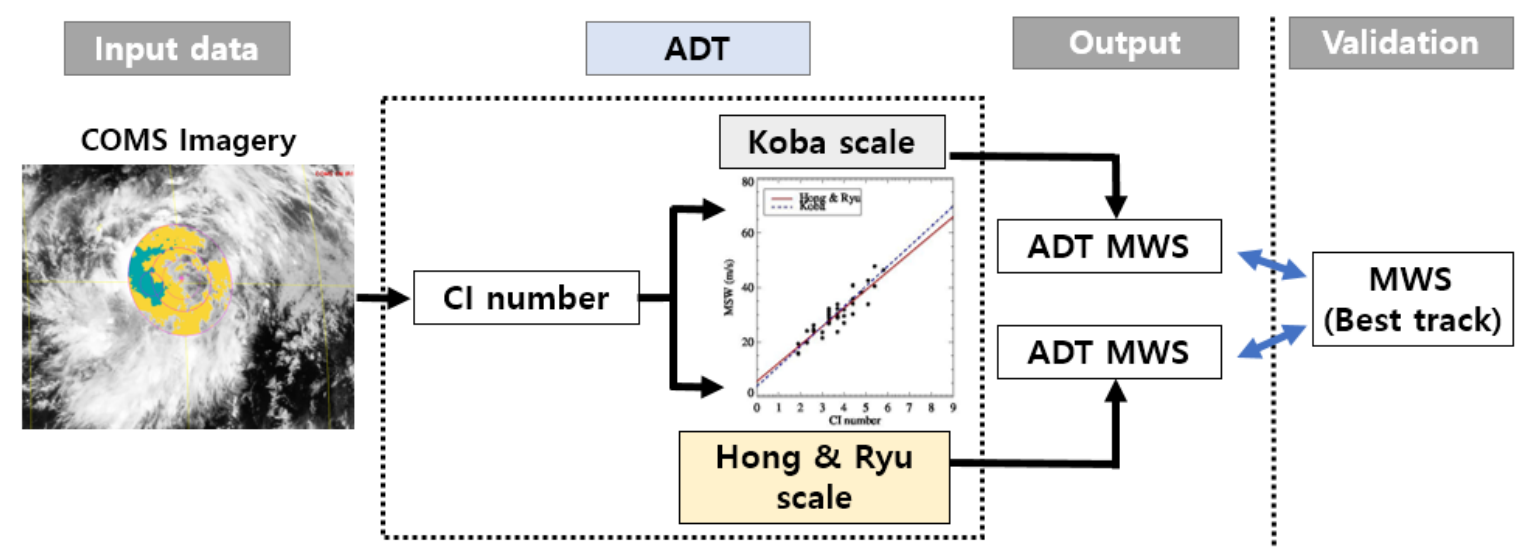

Figure 5. Validation procedure of the Hong and Ryu scale CI to MWS conversion scale for northwestern Pacific TCs.

The accuracy of the Hong and Ryu method is evaluated using basic statistical analysis parameters such as bias, RMSE, and the CC as per the following equations:

$$
\begin{gathered}
\text { Bias }=\frac{1}{N} \sum_{i=1}^{N}\left(W_{i, A}-W_{i, P}\right) \\
M S E=\sqrt{\frac{1}{N} \sum_{i=1}^{N}\left(M W S_{B e s t, i}-M W S_{A D T, i}\right)^{2}} \\
C C=\frac{\sum_{i=1}^{N}\left(M W S_{A D T, i}-\overline{M W S_{A D T}}\right)\left(M W S_{B e s t, i}-\overline{M W S_{B e s t}}\right)}{\sqrt{\sum_{i=1}^{N}\left(M W S_{A D T, i}-\overline{M W S_{A D T}}\right)^{2}} \sqrt{\sum_{i=1}^{N}\left(M W S_{\text {Best }, i}-\overline{M W S_{B e s t}}\right)^{2}}}
\end{gathered}
$$

where $M W S_{B e s t, i}$ is the MWS value of the best track; $M W S_{A D T, i}$ is the MWS value of the ADT; $N$ is the number of data; $i$ is the index from 1 to $N ; \overline{M W S_{\text {Best }}}$ is the average value of the MWS data for best track; and $\overline{M W S_{A D T}}$ is the average value of the MWS data for the ADT.

\section{Results}

Figure 6 shows that the CC $(0.90)$ between the best track and SMAP MWS is higher than the CC of the ADT (0.75). There were 34 data points for spatiotemporal resolution matching among the SMAP, ADT, and best track data for TCs in the study area between 2015 to 2018. In addition, the RMSE for SMAP $(4.03 \mathrm{~m} / \mathrm{s})$ was less than the ADT $(4.66 \mathrm{~m} / \mathrm{s})$ using the Koba scale compared with the MWS of best track during this period. This indicates that SMAP sea surface wind speed data are more directly related to best track data.

Figure 7 shows the MWS computed using each scale depending on the CI number. Table 3 shows that the Hong and Ryu scale yields a higher MWS value than the Koba scale for CI > 3, whilst the former has a lower MWS value than the latter for $\mathrm{CI}<3$. 


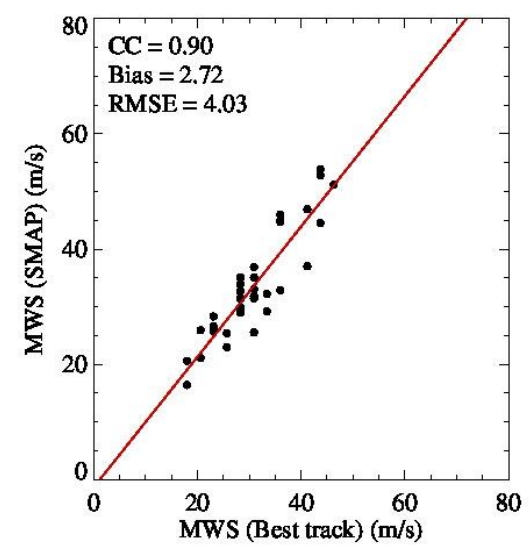

(a)

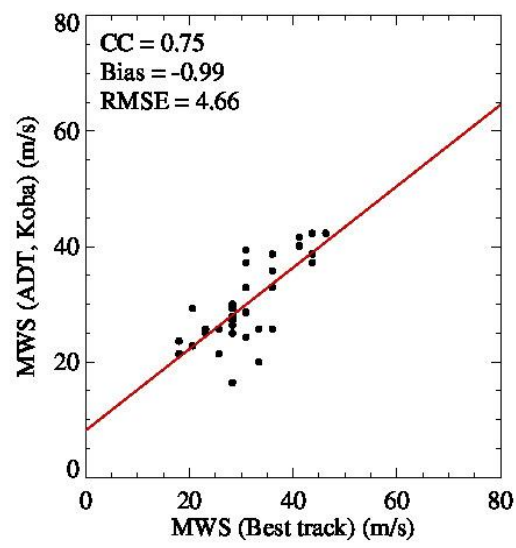

(b)

Figure 6. (a) MWS (best track) vs. MWS (SMAP) and (b) MWS (best track) vs. MWS (Koba scale).

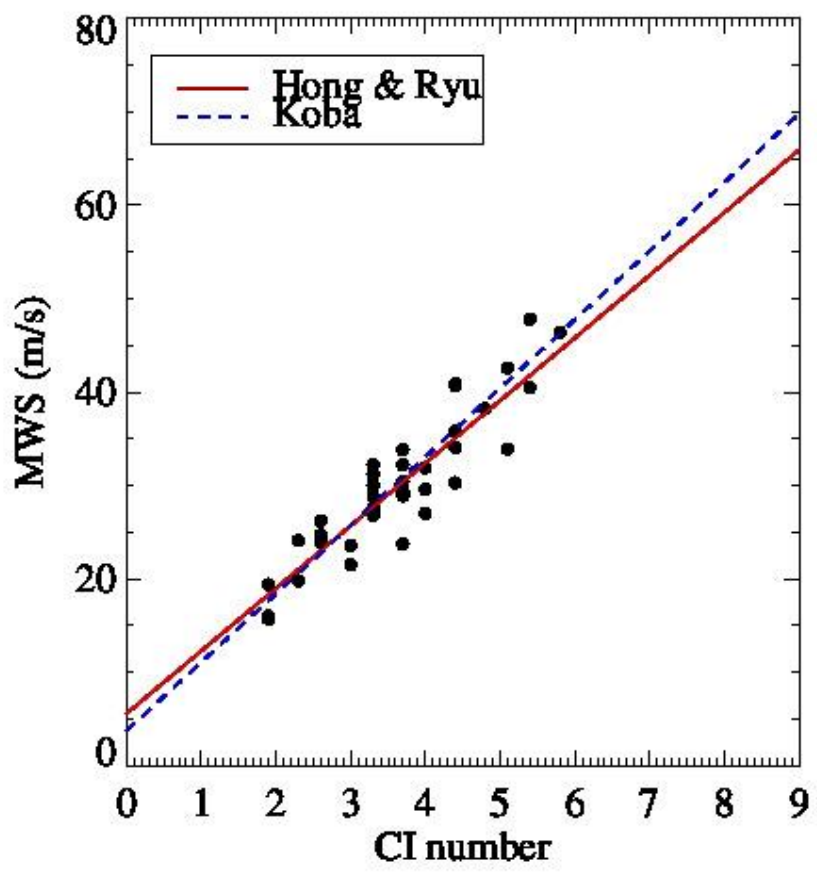

Figure 7. Koba (blue dotted line) and Hong and Ryu (red line) scales depending on the CI number.

Figure 8 compares the results of the new ADT, based on the Hong and Ryu scale, to the best track data for almost all northwestern Pacific TCs between 2015 to 2018 relative to the current ADT based on the Koba scale. The new ADT using the Hong and Ryu scale and the current ADT using the Koba scale both show a CC value of 0.83 . The RMSE of the current ADT based on the Koba scale $(4.71 \mathrm{~m} / \mathrm{s})$ is slightly higher than the new ADT based on the Hong and Ryu scale $(4.34 \mathrm{~m} / \mathrm{s})$. Table 4 presents the RMSEs for each CI number according to the Hong and Ryu and Koba scales calculated using ADT TC intensity data between 2015 to 2018. As seen in Table 3, the Hong and Ryu scale has a lower RMSE value for CI range between 2 to 7 than the Koba scale. For a CI range between 1 to 2 or 7 to 8 , the Koba scale had better results than the Hong and Ryu scale. However, the mean difference between the two scales were very small $(<0.5 \mathrm{~m} / \mathrm{s})$. 
Table 3. Conversion table for Koba and the computed Hong and Ryu scales.

\begin{tabular}{cccc}
\hline CI & MSLP (mb) & MWS (m/s) (Koba Scale) & MWS (m/s) (Hong and Ryu Scale) \\
\hline 1.0 & 1005 & 11.3 & 12.3 \\
\hline 1.5 & 1002 & 14.9 & 15.6 \\
\hline 2.0 & 998 & 18.5 & 19.0 \\
\hline 2.5 & 993 & 22.1 & 22.3 \\
\hline 3.0 & 987 & 25.7 & 25.7 \\
\hline 3.5 & 981 & 29.3 & 29.0 \\
\hline 4.0 & 973 & 32.9 & 32.4 \\
\hline 4.5 & 965 & 36.5 & 35.8 \\
\hline 5.0 & 956 & 40.1 & 39.1 \\
\hline 5.5 & 947 & 43.7 & 42.5 \\
\hline 6.0 & 937 & 47.8 & 45.8 \\
\hline 6.5 & 926 & 51.4 & 49.2 \\
\hline 7.0 & 914 & 55.0 & 52.5 \\
\hline 7.5 & 901 & 59.2 & 55.9 \\
\hline 8.0 & 888 & 62.8 & 59.2 \\
\hline
\end{tabular}

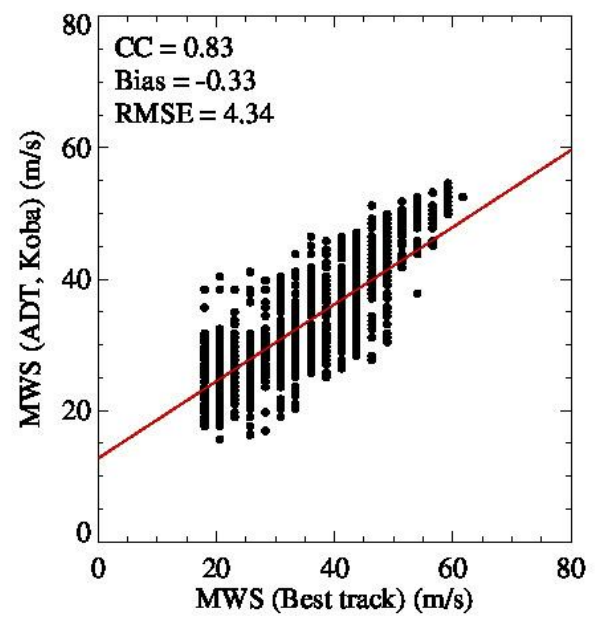

(a)

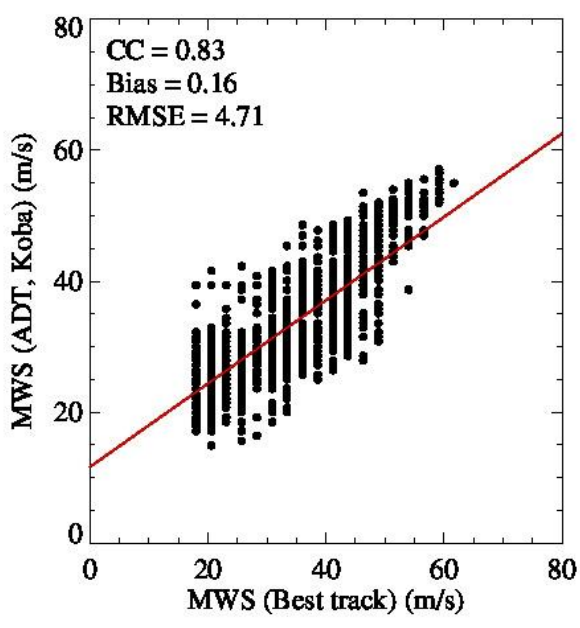

(b)

Figure 8. (a) MWS (best track) vs. MWS (Hong and Ryu scale) and (b) MWS (best track) vs. MWS (Koba scale) between 2015-2018. In this case, the number of data points is 1970.

Table 4. RMSE values for each CI number according to the Hong and Ryu and Koba scales calculated using ADT TC intensity data (2015-2018).

\begin{tabular}{ccc}
\hline CI Number & Hong and Ryu $(\mathrm{m} / \mathbf{s})$ & Koba $(\mathrm{m} / \mathbf{s})$ \\
\hline $1.0-2.0$ & 9.08 & 9.70 \\
\hline $2.0-3.0$ & 3.63 & 3.91 \\
\hline $3.0-4.0$ & 4.03 & 4.38 \\
\hline $4.0-5.0$ & 4.13 & 4.46 \\
\hline $5.0-6.0$ & 4.83 & 5.21 \\
\hline $6.0-7.0$ & 6.02 & 6.71 \\
\hline $7.0-8.0$ & 6.27 & 6.93 \\
\hline
\end{tabular}


Figure 9 illustrates the validation and accuracy of the new ADT based on the Hong and Ryu scale using an independent set of TC cases that occurred in the northwestern Pacific in 2013 and 2014. On this dataset, the new ADT using the Hong and Ryu scale and the current ADT using the Koba scale both yield a MWS CC of 0.84 with JMA best track MWS. The new ADT using the Hong and Ryu scale produce a lower bias of $0.85 \mathrm{~m} / \mathrm{s}$ and RMSE of $4.39 \mathrm{~m} / \mathrm{s}$, compared to the current ADT with a bias of $1.40 \mathrm{~m} / \mathrm{s}$ and RMSE of $4.77 \mathrm{~m} / \mathrm{s}$. Table 5 details the RMSEs for each CI number according to the Hong and Ryu and Koba scales using ADT TC intensity data from 2013 and 2014. Notably, the Hong and Ryu scale generates lower RMSE values than the Koba scale in all ranges of the CI number.

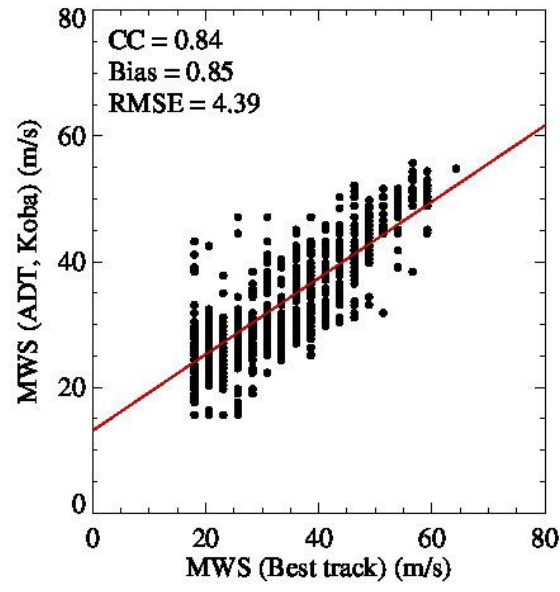

(a)

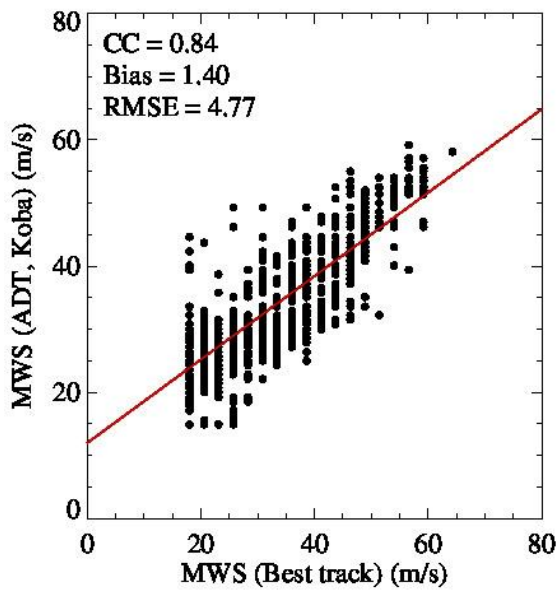

(b)

Figure 9. (a) MWS (best track) vs. MWS (Hong and Ryu scale) and (b) MWS (best track) vs. MWS (Koba scale) for an independent sample of northwestern Pacific TCs in 2013-2014.

Table 5. RMSEs values for each CI number according to the Hong and Ryu and Koba scales using the ADT TC intensity data (2013-2014).

\begin{tabular}{ccc}
\hline CI Number & Hong and Ryu $(\mathrm{m} / \mathbf{s})$ & Koba $(\mathrm{m} / \mathbf{s})$ \\
\hline $1.0-2.0$ & 10.66 & 11.42 \\
\hline $2.0-3.0$ & 3.89 & 4.17 \\
\hline $3.0-4.0$ & 3.55 & 3.87 \\
\hline $4.0-5.0$ & 4.32 & 4.69 \\
\hline $5.0-6.0$ & 5.43 & 5.83 \\
\hline $6.0-7.0$ & 5.54 & 6.21 \\
\hline $7.0-8.0$ & 5.59 & 6.48 \\
\hline
\end{tabular}

The performance results over the two periods (2015 to 2018 and 2013 to 2014) have similar values of CC between the two scales. However, the RMSE of the Hong and Ryu conversion scale is a notable improvement over the existing Koba scale when used with the ADT. These validation results indicate that the Hong and Ryu scale shows potential for improving ADT estimates of TC intensity information in the northwestern Pacific region.

\section{Discussion}

The improvements and limitations of this new Hong and Ryu scale are illustrated with some TC examples shown in Figure 10. TCs Jebi in 2013, Rammasun in 2014, and Haima in 2016 can be classified as violent typhoons; their intensities were calculated using the ADT with both MWS conversion scales. The performance of the ADT with the Hong and Ryu scale is similar to or better than the ADT based on 
the Koba scale for typhoons and strong typhoons (wind speeds ranging between $20-50 \mathrm{~m} / \mathrm{s}$ ), but the latter shows slightly better results than the former for violent typhoons (wind speed $>50 \mathrm{~m} / \mathrm{s}$ ). This is attributable to the physical limitation of SMAP wind speed retrievals, arising from the saturation of brightness temperatures in the L-band. The Hong and Ryu scale could, therefore, be improved with a future microwave instrument capable of sensing wavelengths exceeding the L-band.

This study is limited in that there was only a small collocated northwestern Pacific TC match dataset available for developing the Hong and Ryu scale due to the infrequent SMAP overpasses since June 2015. As such, additional experiments will be conducted including sea surface wind speed data from the Soil Moisture and Ocean Salinity (SMOS) satellite [25] and aircraft reconnaissance observations from the Stepped Frequency Microwave Radiometer (SFMR) [26-31].

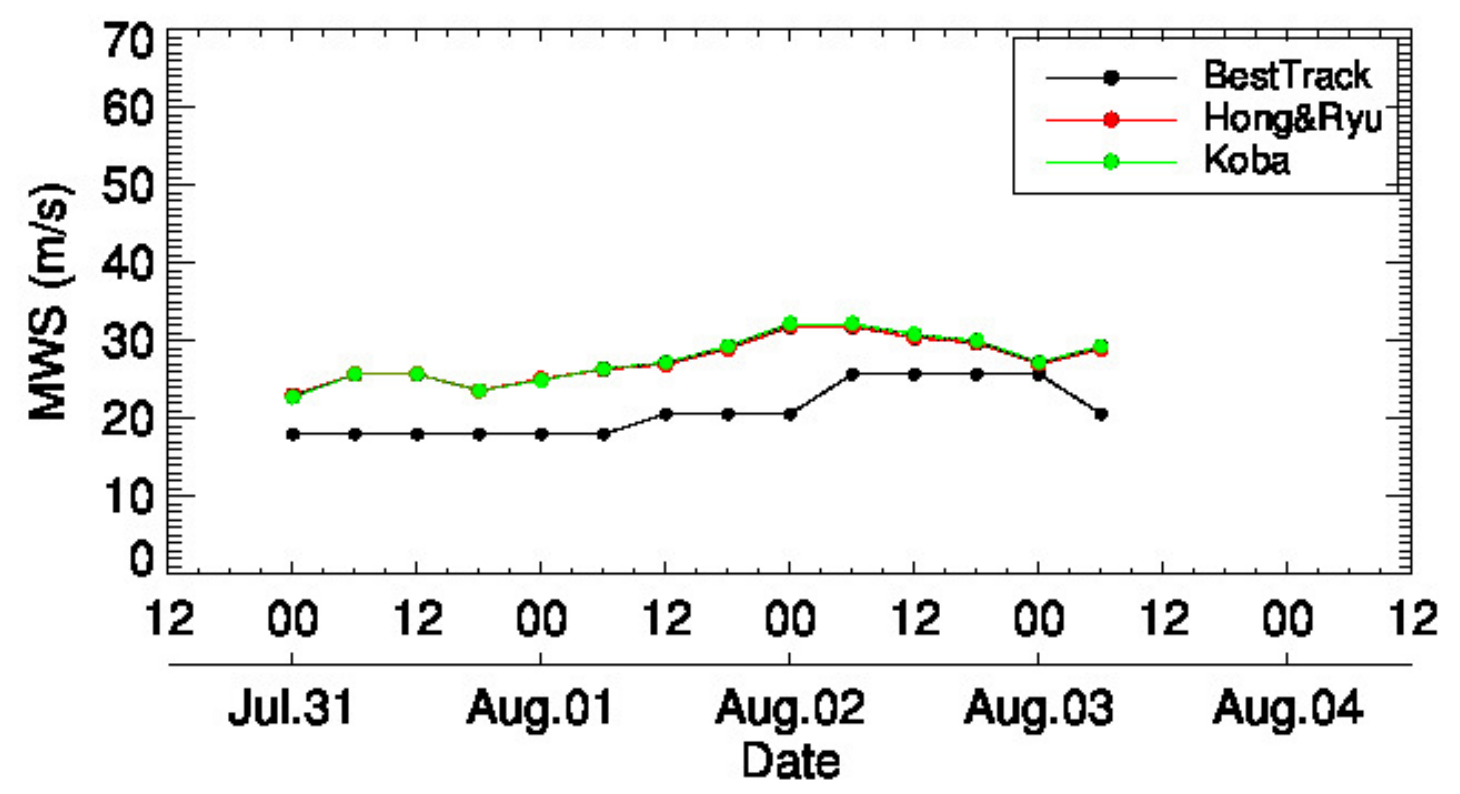

(a)

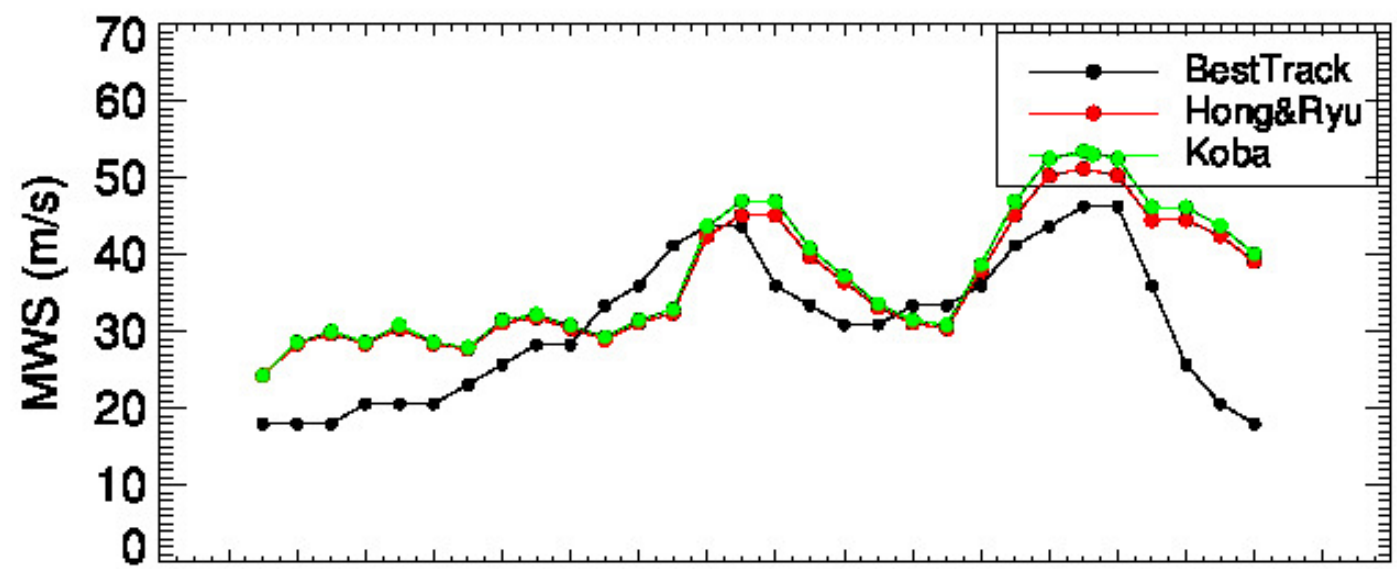

12001200120012001200120012001200120012

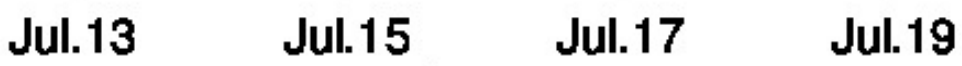

Date

(b)

Figure 10. Cont. 


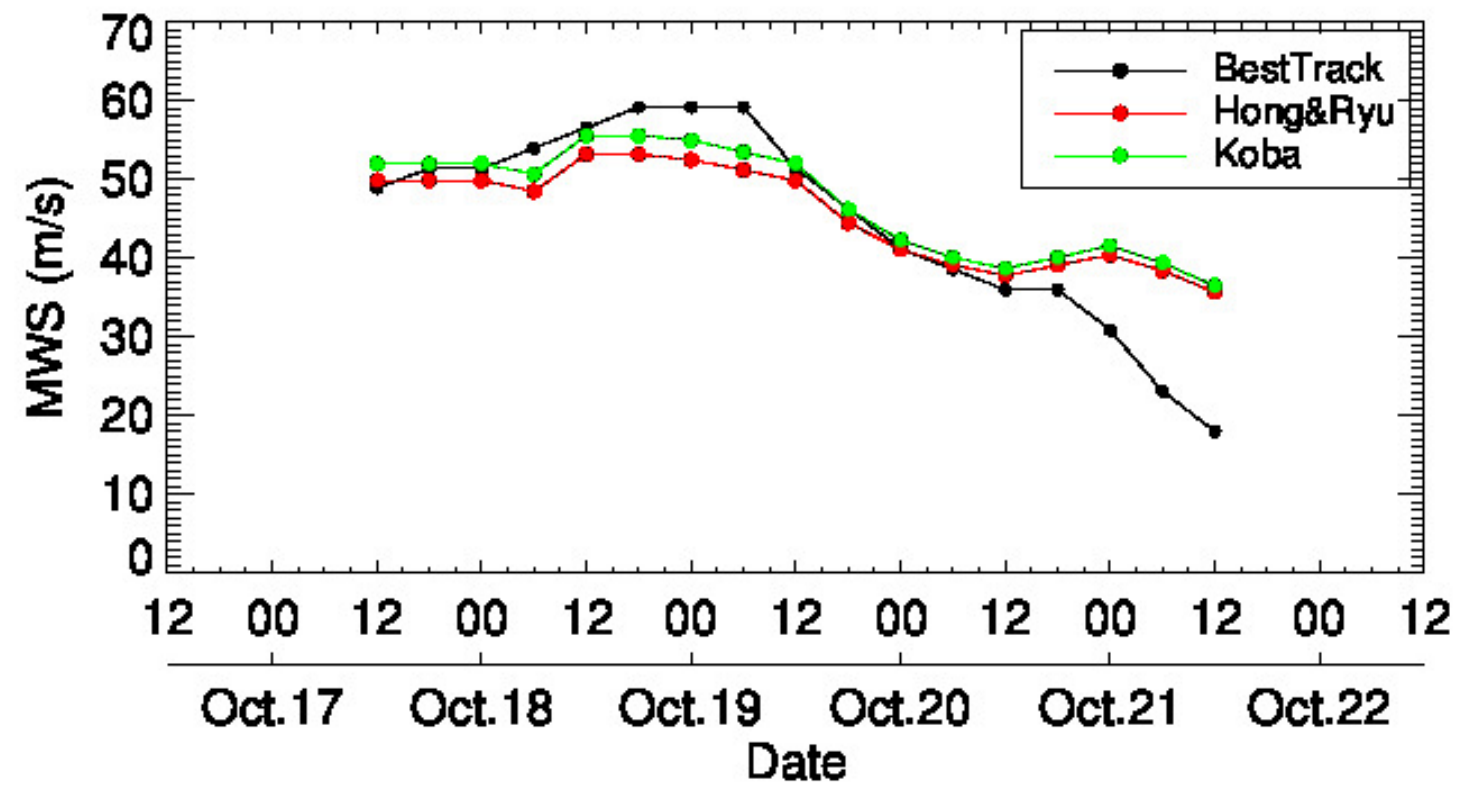

(c)

Figure 10. Time series of estimated maximum wind speeds for three typhoons: (a) Jebi in 2013, (b) Rammasun in 2014, and (c) Haima in 2016, derived from the best track, and two ADTs with the Koba and Hong and Ryu scales.

\section{Summary and Concluding Remarks}

The meteorological agencies in the northwestern Pacific TC basin, including Korea, have traditionally applied the Koba conversion scale to estimate the maximum wind speed of TCs from the Advanced Dvorak Technique current intensity values. This study presents an alternative conversion scale to apply with the ADT based on calibrated observations from the SMAP L-band radiometer.

The sea surface wind speed data from SMAP, TC intensity data from the ADT with the Koba scale, and the MWS data of the best track MWS from 2015 to 2018 are used to confirm that the SMAP wind speed data agrees well with the best track MWS. We then developed a new ADT CI to MWS conversion scale, the Hong and Ryu scale, based on the SMAP sea surface wind speed data. The new ADT MWS estimates based on the Hong and Ryu scale are then compared to the current ADT using the Koba scale based on a large sample of northwestern Pacific TC cases from 2015 to 2018. The new ADT using the Hong and Ryu scale shows a lower RMSE than the current ADT using the Koba scale. To verify these results on an independent sample, the new ADT MWS results are compared to the current ADT estimates using northwestern Pacific TC cases from 2013 to 2014. This validation effort demonstrates that the MWS estimates from the new ADT show a modest improvement compared to the MWS estimates from the current ADT. In the northwestern Pacific, the proposed Hong and Ryu scale shows an improved performance for MWSs ranging between 20-50 m/s, whereas the Koba scale shows slightly better results for MWSs $>50 \mathrm{~m} / \mathrm{s}$ owing to the saturation issues with brightness temperatures in the SMAP L-band sensor at high intensities. A merging of the Koba scale and the Hong and Ryu scale to handle the discontinuity at $50 \mathrm{~m} / \mathrm{s}$ can be a future work.

The findings in this study are expected to make scientific and socio-economic contributions to improve TC intensity analysis and information disseminated to the public in the northwestern Pacific region. 
Author Contributions: Conceptualization, S.H.; methodology, S.R. and S.H.; software, S.R.; validation, S.R. and S.H.; formal analysis, S.R and S.H.; investigation, S.R. and S.H.; resources, S.H.; data curation, S.-E.H., J.-D.P. and S.H.; writing—original draft preparation, S.R. and S.H.; writing—review and editing, S.H.; visualization, S.R.; supervision, S.H.; project administration, S.H.; funding acquisition, S.H. All authors have read and agreed to the published version of the manuscript.

Funding: This work was supported by the Korea Meteorological Administration Research and Development Program under Grant KMI2020-00510.

Acknowledgments: The authors thank anonymous reviewers for constructive and helpful comments on the manuscript.

Conflicts of Interest: The authors declare no conflicts of interest.

\section{References}

1. Takagi, H.; Esteban, M.; Shibayama, T.; Mikami, T.; Matsumaru, R.; De Leon, M.; Thao, N.D.; Oyama, T.; Nakamura, R. Track analysis, simulation, and field survey of the 2013 typhoon Haiyan storm surge. J. Flood Risk Manag. 2017, 10, 42-52. [CrossRef]

2. Dvorak, V.F. A Technique for the Analysis and Forecasting of Tropical Cyclone Intensities from Satellite Pictures; US Department of Commerce, National Oceanic and Atmospheric Administration, National Environmental Satellite Service: Silver Spring, MD, USA, 1972.

3. Dvorak, V.F. Tropical cyclone intensity analysis and forecasting from satellite imagery. Mon. Weather Rev. 1975, 103, 420-430. [CrossRef]

4. Dvorak, V.F. Tropical Cyclone Intensity Analysis Using Satellite Data; US Department of Commerce, National Oceanic and Atmospheric Administration, National Environmental Satellite, Data, and Information Service: Silver Spring, MD, USA, 1984.

5. Velden, C.; Harper, B.; Wells, F.; Beven, J.L.; Zehr, R.; Olander, T.; Mayfield, M.; Guard, C.C.; Lander, M.; Edson, R. Supplement to: The Dvorak tropical cyclone intensity estimation technique: A satellite-based method that has endured for over 30 years. Bull. Am. Meteorol. Soc. 2006, 87, S6-S9. [CrossRef]

6. Koba, H.; Hagiwara, T.; Osano, S.; Akashi, S. Relationship between the CI-number and central pressure and maximum wind speed in typhoons. J. Meteor. Res. 1990, 42, 59-67.

7. Harper, B. Tropical Cyclone Parameter Estimation in the Australian Region; Systems Engineering Australia Pty Ltd. for Woodside Energy Ltd.: Perth, Australia, 2002.

8. Knaff, J.A.; Zehr, R.M. Reexamination of tropical cyclone wind-pressure relationships. Weather Forecast. 2007, 22, 71-88. [CrossRef]

9. Holland, G. A revised hurricane pressure-Wind model. Mon. Weather Rev. 2008, 136, 3432-3445. [CrossRef]

10. Courtney, J. Adapting the Knaff and Zehr wind-pressure relationship for operational use in Tropical Cyclone Warning Centres. Aust. Meteorol. Oceanogr. J. 2009, 58, 167. [CrossRef]

11. Koba, H.; Hagiwara, T.; Osano, S.; Akashi, S. Relationships between CI number and minimum sea level pressure/maximum wind speed of tropical cyclones. Geophys. Mag. 1991, 44, 15-25.

12. Olander, T.L.; Velden, C.S. The advanced Dvorak technique: Continued development of an objective scheme to estimate tropical cyclone intensity using geostationary infrared satellite imagery. Weather Forecast. 2007, 22, 287-298. [CrossRef]

13. Olander, T.L.; Velden, C.S. The advanced Dvorak technique (ADT) for estimating tropical cyclone intensity: Update and new capabilities. Weather Forecast. 2019, 34, 905-922. [CrossRef]

14. Reul, N.; Chapron, B.; Zabolotskikh, E.; Donlon, C.; Quilfen, Y.; Guimbard, S.; Piolle, J.-F. A revised L-band radio-brightness sensitivity to extreme winds under tropical cyclones: The five year SMOS-storm database. Rem. Sens. Environ. 2016, 180, 274-291. [CrossRef]

15. Reul, N.; Tenerelli, J.; Chapron, B.; Vandemark, D.; Quilfen, Y.; Kerr, Y. SMOS satellite L-band radiometer: A new capability for ocean surface remote sensing in hurricanes. J. Geophys. Res. 2012, 117, 1-24. [CrossRef]

16. Meissner, T.; Ricciardulli, L.; Wentz, F.J. Capability of the SMAP mission to measure ocean surface winds in storms. Bull. Am. Meteorol. Soc. 2017, 98, 1660-1677. [CrossRef]

17. Yueh, S.H.; Fore, A.G.; Tang, W.; Hayashi, A.; Stiles, B.; Reul, N.; Weng, Y.; Zhang, F. SMAP L-band passive microwave observations of ocean surface wind during severe storms. IEEE Trans. Geosci. Remote Sens. 2016, 54, 7339-7350. [CrossRef] 
18. Meissner, T.; Ricciardulli, L.; Wentz, F. Remote Sensing Systems SMAP Daily Sea Surface Winds Speeds on 0.25 Deg Grid, Version 01.0. [NRT or FINAL]. Remote Sensing Systems, Santa Rosa, CA. 2018. Available online: http://www.remss.com/missions/smap/ (accessed on 21 July 2019).

19. Kim, Y.; Hong, S. Deep learning-generated nighttime reflectance and daytime radiance of the midwave infrared band of a geostationary satellite. Rem. Sens. 2019, 11, 2713. [CrossRef]

20. Entekhabi, D.; Njoku, E.G.; O’Neill, P.E.; Kellogg, K.H.; Crow, W.T.; Edelstein, W.N.; Entin, J.K.; Goodman, S.D.; Jackson, T.J.; Johnson, J. The soil moisture active passive (SMAP) mission. Proc. IEEE 2010, 98, 704-716. [CrossRef]

21. Hong, S.; Seo, H.-J.; Kim, N.; Shin, I. Physical retrieval of tropical ocean surface wind speed under rain-free conditions using spaceborne microwave radiometers. Rem. Sens. Lett. 2015, 6, 380-389. [CrossRef]

22. Hong, S.; Shin, I. Wind speed retrieval based on sea surface roughness measurements from spaceborne microwave radiometers. J. Appl. Meteorol. Climatol. 2013, 52, 507-516. [CrossRef]

23. Knapp, K.R.; Kruk, M.C.; Levinson, D.H.; Diamond, H.J.; Neumann, C.J. The international best track archive for climate stewardship (IBTrACS) unifying tropical cyclone data. Bull. Am. Meteorol. Soc. 2010, 91, 363-376. [CrossRef]

24. Hong, S.; Seo, H.-J.; Kwon, Y.-J. A unique satellite-based sea surface wind speed algorithm and its application in tropical cyclone intensity analysis. J. Atmos. Ocean. Technol. 2016, 33, 1363-1375. [CrossRef]

25. Cotton, J.; Francis, P.; Heming, J.; Forsythe, M.; Reul, N.; Donlon, C. Assimilation of SMOS L-band wind speeds: Impact on met office global NWP and tropical cyclone predictions. Q. J. R. Meteorol. Soc. 2018, 144, 614-629. [CrossRef]

26. Aberson, S.D.; Black, M.L.; Black, R.A.; Cione, J.J.; Landsea, C.W.; Marks, F.D., Jr.; Burpee, R.W. Thirty years of tropical cyclone research with the NOAA P-3 aircraft. Bull. Am. Meteorol. Soc. 2006, 87, 1039-1055. [CrossRef]

27. Gray, W.M.; Neumann, C.; Tsui, T.L. Assessment of the role of aircraft reconnaissance on tropical cyclone analysis and forecasting. Bull. Am. Meteorol. Soc. 1991, 72, 1867-1883. [CrossRef]

28. Rogers, R.; Aberson, S.; Black, M.; Black, P.; Cione, J.; Dodge, P.; Gamache, J.; Kaplan, J.; Powell, M.; Dunion, J. The intensity forecasting experiment: A NOAA multiyear field program for improving tropical cyclone intensity forecasts. Bull. Am. Meteorol. Soc. 2006, 87, 1523-1537. [CrossRef]

29. Rogers, R.; Aberson, S.; Aksoy, A.; Annane, B.; Black, M.; Cione, J.; Dorst, N.; Dunion, J.; Gamache, J.; Goldenberg, S. NOAA's hurricane intensity forecasting experiment: A progress report. Bull. Am. Meteorol. Soc. 2013, 94, 859-882. [CrossRef]

30. Uhlhorn, E.W.; Black, P.G. Verification of Remotely Sensed Sea Surface Winds in Hurricanes. J. Atmos. Ocean. Technol. 2003, 20,99-116. [CrossRef]

31. Uhlhorn, E.W.; Black, P.G.; Franklin, J.L.; Goodberlet, M.; Carswell, J.; Goldstein, A.S. Hurricane surface wind measurements from an operational stepped frequency microwave radiometer. Mon. Weather Rev. 2007, 135, 3070-3085. [CrossRef]

(C) 2020 by the authors. Licensee MDPI, Basel, Switzerland. This article is an open access article distributed under the terms and conditions of the Creative Commons Attribution (CC BY) license (http://creativecommons.org/licenses/by/4.0/). 